\title{
Glasshouse Evaluation of New Source of Resistance against Brown Plant Hopper Nilaparvata lugens (Stal) in Rice
}

\author{
Vijay Kumar Soni ${ }^{1 *}$ and S.N. Tiwari ${ }^{2}$ \\ ${ }^{1}$ Department of Entomology, S. K. College of Agriculture and Research Station, \\ IGKV, Kawardha (Kabirdham) 491 995, Chhattisgarh, India \\ ${ }^{2}$ Department of Entomology, G.B. Pant University of Agriculture and Technology, \\ Pantnagar (U.S. Nagar) 263 145, Uttarakhand, India \\ *Corresponding author
}

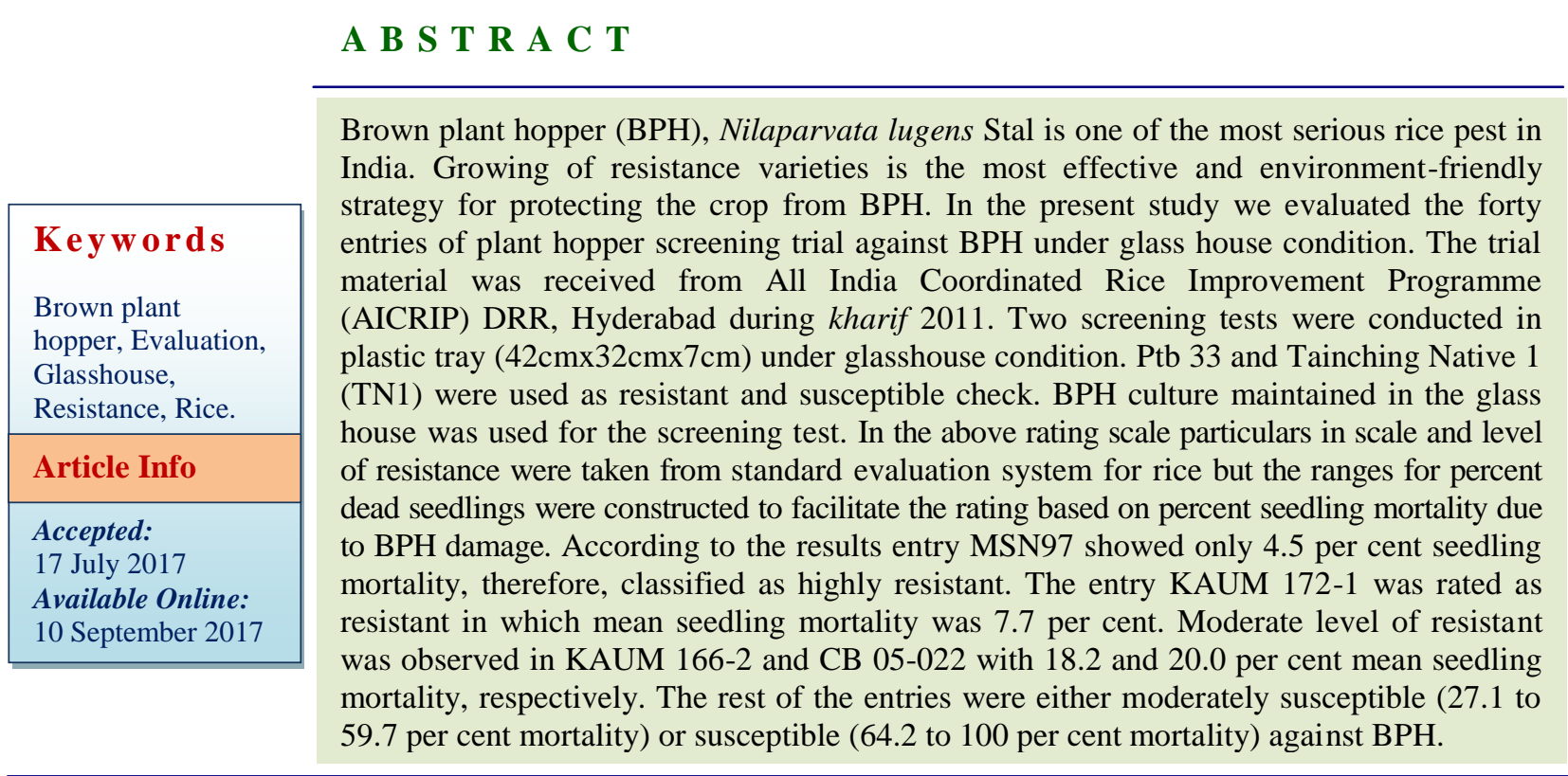

\section{Introduction}

Rice (Oryza sativa L.) is an ancient and the most genetically diversified cereal crop. Approximately half of the people on earth obtain the majority of their caloric intake from rice. Rice harbour more than 100 insect pest species. Among these, brown planthopper (BPH), Nilaparvata lugens (Stål) belongs to the Family Delphacidae and Order Hemiptera, is probably the most important pest of rice in Asia and India.
Plant responses with direct or indirect deleterious effects from the attack of $\mathrm{BPH}$ including reduction in the plant growth (root development, plant height and reproduction), wilting and leaf chlorosis. Collectively these symptoms are acknowledged as 'hopper burn'. BPH losses in grain yield ranges from $10 \%$ in moderately affected fields to $70 \%$ in those severely affected and the damage to the standing crop sometimes reached 100\% 
(Krishnaiah et al., 2008). Insecticide proves to be the only option where we can rely for emergency management of insect pest reaching on or beyond ETL. But the indiscriminate use of broad spectrum chemicals reduces the biodiversity of natural enemies, lift the natural control, induce outbreak of secondary pests, residue problem in the grains and contaminate eco-system (Singh, 2000) resulted in resurgence of brown planthopper (Heinrichs and Mochida, 1984; Kenmore et al., 1984).

Moreover in the present WTO era where a lot of stress is given on quality parameters, the search for alternate methods of control BPH becomes important. Exploitation of Host Plant Resistance (HPR) is a major component to manage this pest. The development of rice varieties (Oryza sativa L.) that are resistant to the $\mathrm{BPH}$ is an important objective in current breeding programmes (Park et al., 2007). Growing resistant varieties is the most effective and environment-friendly strategy for protecting the crop from BPH.

Thus, the present studies were conducted to identify the new sources of resistance against $\mathrm{BPH}$ in rice under glass house condition.

\section{Materials and Methods}

The screening of rice genotypes at seedling stage against BPH were conducted in the glasshouse of Department of Entomology, G.B. Pant University of Agriculture and Technology, Pantnagar during Kharif 2011. Two screening trials conducted during Kharif 2011. Seed bed screening method was used for screening of entries. The purpose of bulk screening was to reject the susceptible ones and to find out entries showing moderate to high level of resistance against BPH. Both the screening tests were done in plastic tray size of $42 \mathrm{~cm} \times 32 \mathrm{~cm} \times 7 \mathrm{~cm}$ in glasshouse. Following screening procedure was used:

\section{Sources of PHS entries}

Plant hopper screening (PHS) entries (Table 1) received from All India Co-ordinated Rice Improvement Programme (AICRIP) during kharif 2011 were evaluated against brown plant hopper in both the screening trials.

\section{Seed germination}

Plastic petridishes were marked with respective entry number of PHS and fifty seeds of each entry were kept on double layered moist filter papers. Water was added to each petridish for seed soaking which was removed after 24 hours. Thereafter, petridishes were placed in incubator maintained at $30^{\circ} \mathrm{C}$ temperature for efficient germination. Sufficient moisture was maintained in each petridish till germinated seeds were sown into tray.

\section{Preparation of seed bed for sowing}

The plastic tray $(42 \mathrm{~cm} \times 32 \mathrm{~cm} \times 7 \mathrm{~cm})$ was filled with well manured soil up to the sufficient height so that $5 \mathrm{~cm}$ water level could be maintained above the soil surface. Soil was puddled properly and upper layer was leveled uniformly with the help of a smooth object to facilitate sowing.

\section{Seed sowing and maintenance of test seedlings}

The germinated seeds of each test entry were sown in the tray with the help of forceps. Single row of each entry with 20 pregerminated seeds was sown and labeled with ice-cream sticks containing entry numbers. The distance between the rows was maintained at $4 \mathrm{~cm}$ apart, while distance between seeds was kept at $1 \mathrm{~cm}$. After completing the sowing sufficient water was added daily to ensure the healthy growth of seedlings. 


\section{Mass rearing of brown plant hoppers}

A laboratory population of $N$. lugens were maintained on the plants of Oryza sativa L. (cv: TN1) in pots in glasshouse. The temperature of glasshouse was maintained from 25 to $30^{\circ} \mathrm{C}$ during the study period. The $2^{\text {nd }}$ and $3^{\text {rd }}$ instar nymphs of BPH from this culture were used for the infestation.

\section{Infestation of seedlings with BPH}

At 12 days after sowing (DAS) tray was filled with $5 \mathrm{~cm}$ water level and each row was thinned to about 20 seedlings / row after which the $2^{\text {nd }}$ and $3^{\text {rd }}$ instar nymphs of $\mathrm{BPH}$ from the culture were distributed uniformly on the test entries at the rate of approximately 10 nymphs per seedling.

\section{Gradation of the test entries}

The final score was taken when the seedlings of susceptible check variety TN-1 became 100 percent dead. The rating was based on the following scoring system:
In the above rating scale particulars in 'scale' 'and level of resistance' were taken from Heinrichs et al., (1985) but the ranges for percent dead seedlings were constructed to facilitate the rating based on percent seedling mortality due to BPH damage.

\section{Results and Discussion}

The mean seedling mortality ranged from 4.5 to 100 per cent in the different entries screened against BPH (Table 1). The mean of two screening tests indicated that MSN97 (33) showed only 4.5 per cent seedling mortality, so, classified as highly resistant (HR). The entry KAUM 172-1(19) was rated as resistant (R) in which mean seedling mortality was 7.7 per cent. Moderate level of resistant (MR) was observed in KAUM 166-2 (17) and CB 05-022(36) with 18.2 and 20.0 per cent mean seedling mortality, respectively. The rest of the entries were either moderately susceptible (MS) (27.1 to 59.7 per cent mortality) or susceptible (S) against BPH due to the 64.2 to 100 per cent mortality of seedlings.

Rating scale

\begin{tabular}{c|cl}
\hline Scale & Percent dead seedlings & \multicolumn{1}{c}{ Level of resistance } \\
\hline 0 & 0 & Immune (I) \\
1 & $1-5$ & Highly resistant (HR) \\
3 & $6-9$ & Resistant (R) \\
5 & $10-25$ & Moderately resistant (MR) \\
7 & $26-60$ & Moderately susceptible (MS) \\
9 & $61-100$ & Susceptible (S) \\
\hline
\end{tabular}


Int.J.Curr.Microbiol.App.Sci (2017) 6(9): 1187-1192

Table.1 Evaluation of PHS entries against $N$. lugens under glasshouse condition

\begin{tabular}{|c|c|c|c|c|c|c|c|}
\hline \multirow{2}{*}{$\begin{array}{l}\text { Ent. } \\
\text { No }\end{array}$} & \multirow{2}{*}{ Designation } & \multirow{2}{*}{ Cross } & \multicolumn{2}{|c|}{$\begin{array}{l}\text { Per cent seedling } \\
\text { mortality }\end{array}$} & \multirow{2}{*}{$\begin{array}{c}\text { Mean } \\
\text { mortality } \\
(\%)\end{array}$} & \multirow{2}{*}{$\begin{array}{l}\text { Final } \\
\text { score }\end{array}$} & \multirow{2}{*}{$\begin{array}{l}\text { Resistance } \\
\text { grade }^{* *}\end{array}$} \\
\hline & & & $\begin{array}{c}\text { I } \\
\text { screening* }\end{array}$ & $\begin{array}{c}\text { II } \\
\text { screening* }\end{array}$ & & & \\
\hline 1 & CB 07103 & Swarna/CO 43 & - & $33.3(7)$ & 33.3 & 7 & MS \\
\hline 2 & CB 07537 & CO47/JGL 1798 & $25.0(5)$ & $36.4(7)$ & 30.7 & 7 & MS \\
\hline 5 & CB 08504 & Rasacdam/IR 50 & $66.7(9)$ & $23.1(5)$ & 44.9 & 7 & MS \\
\hline 6 & CB 08254 & BPT 5204 /IR 64 & $100.0(9)$ & $90.0(9)$ & 95.0 & 9 & $\mathrm{~S}$ \\
\hline 7 & CB 08534 & JGL 384/ Rasi & $100.0(9)$ & $66.7(9)$ & 83.3 & 9 & S \\
\hline 8 & CB 08721 & ADT $43 /$ IR 20 & $100.0(9)$ & $75.0(9)$ & 87.5 & 9 & S \\
\hline 12 & CB 09142 & WGL 14 /Rasi & $44.4(7)$ & $30.0(7)$ & 37.2 & 7 & MS \\
\hline 13 & CB 09153 & BPT 1788/GEB 24 & - & - & - & - & - \\
\hline 14 & CB 09507 & PMK (R)3 /RR1025 & $69.2(9)$ & $66.7(9)$ & 67.9 & 9 & $\mathrm{~S}$ \\
\hline 15 & CB 09516 & RR 4065-381-245/UPR 2893-93 & $61.5(9)$ & $56.3(7)$ & 58.9 & 7 & MS \\
\hline 16 & KAUM 164-1 & Remanika / Gouri & $64.3(9)$ & $15.4(5)$ & 39.8 & 7 & MS \\
\hline 17 & KAUM 166-2 & Makom /PTB 9 & $18.2(5)$ & $18.2(5)$ & 18.2 & 5 & MR \\
\hline 18 & KAUM 168-1 & Pavizham /Arikkilari & & & & & \\
\hline 19 & KAUM 172-1 & Aiswarya/Karthika & $7.1(3)$ & $8.3(3)$ & 7.7 & 3 & $\mathrm{R}$ \\
\hline 20 & CHECK & PTB 33 & - & - & - & - & - \\
\hline
\end{tabular}


Int.J.Curr.Microbiol.App.Sci (2017) 6(9): 1187-1192

\begin{tabular}{|c|c|c|c|c|c|c|c|}
\hline 21 & KAUM 173-1 & Kanakom /Gouri & - & - & - & - & - \\
\hline 22 & KAUM 173-3 & Kanakom /Gouri & $33.3(7)$ & $62.5(9)$ & 47.9 & 7 & MS \\
\hline 23 & KAUM 173-4 & Kanakom /Gouri & - & $76.9(9)$ & 76.9 & 9 & $\mathrm{~S}$ \\
\hline 24 & KAUM 174-4 & Uma / Gouri & $40.0(7)$ & $72.7(9)$ & 56.4 & 7 & MS \\
\hline 25 & KAUM 174-5 & Uma / Gouri & $41.7(7)$ & $77.8(9)$ & 59.7 & 7 & MS \\
\hline 26 & KAUM 174-6 & Uma / Gouri & $20.0(5)$ & $75.0(9)$ & 47.5 & 7 & MS \\
\hline 27 & KAUM 174-7 & Uma / Gouri & $85.7(9)$ & $62.5(9)$ & 74.1 & 9 & $\mathrm{~S}$ \\
\hline 28 & KAUM 176-4 & Gouri / Uma & - & - & - & - & - \\
\hline 29 & KAUM 177-1 & Uma /Aruna & $57.1(7)$ & 0.0 & 28.6 & 7 & MS \\
\hline 30 & CHECK & MO 1 & - & - & - & - & - \\
\hline 31 & $\begin{array}{l}\text { KAUM 178-1-1- } \\
1\end{array}$ & Gouri /Aruna & $100.0(9)$ & - & 100.0 & 9 & $\mathrm{~S}$ \\
\hline 32 & KMP 194 & IR 64 / O. Rufipogan & $41.7(7)$ & $80.0(9)$ & 60.8 & 7 & MS \\
\hline 33 & MSN 97 & - & $0.0(0)$ & $9.1(3)$ & 4.5 & 1 & HR \\
\hline 34 & $230(\mathrm{~S})$ & RP Bio 4918 & - & - & - & - & - \\
\hline 35 & $212(\mathrm{~S})$ & - & $40.0(7)$ & $14.3(5)$ & 27.1 & 7 & MS \\
\hline 36 & CB 05-022 & CO 43 /ADT 39 & $40.0(7)$ & $0.0(0)$ & 20.0 & 5 & MR \\
\hline 37 & CB 05-031 & CO 43/TNAU 91043 & $100.0(9)$ & $0.0(0)$ & 50.0 & 7 & MS \\
\hline 38 & CB 05-754 & $\begin{array}{l}\text { MTU } 1066 \text { /RR 272-662/PMK3/IR } \\
64\end{array}$ & $58.3(7)$ & $70.0(9)$ & 64.2 & 9 & $\mathrm{~S}$ \\
\hline 39 & CO 06-124 & BPT 5204/ Jeeraga Samba & $57.1(7)$ & $38.5(7)$ & 47.8 & 7 & MS \\
\hline 40 & CHECK & RP 2068-18-3-5 & $66.7(9)$ & - & 66.7 & 9 & $\mathrm{~S}$ \\
\hline
\end{tabular}

$-=$ Seed did not germinate

* Values in parentheses are score given at each screening test

** I= Immune, HR= Highly Resistant, $\mathrm{R}=$ Resistant, MR=Moderately Resistant, MS=Moderately Susceptible, $\mathrm{S}=$ Susceptible 
The results indicated that reaction of entries against BPH varied in different screening tests. However, entries such as MSN97 and KAUM 172-1 performed better against BPH in both the tests under glasshouse condition. Entry KAUM 172-1 which was resistant in our study also gave promising reaction against BPH attack at other locations of India under greenhouse test (Anonymous, 2011). Other entry viz. KAUM 166-2 also showed resistance reaction at different locations (Anonymous, 2011) was considered as moderately resistant against $\mathrm{BPH}$ in our investigation.

\section{References}

Anonymous, 2011. Progress Report Entomology and Pathology. All India Co-ordinated Rice Improvement Pogramme. Directorate of Rice Research, Hyderabad, India. Vol. 2.

Heinrichs, E.A., and Mochida O 1984. From secondary to major pest status. The case of insecticide-induced rice brown plant hopper, Nilaparvata lugens resurgence. Protection Ecology 7:201-218.

Heinrichs, E.A., Medrano F G and Rapusas H $\mathrm{R}$ 1985. Genetic evaluation for insect resistance in rice. IRRI, Los Banos, Philippines 356.

Kenmore, P.E., Carino F D, Perez C A, Dyck V A and Gutierrez A P 1984. Population regulation of the rice brown planthopper (Nilaparvata lugens Stal) within rice fields in the Philippines. Journal of Plant Protection Tropical, 1:19-37.

Krishnaiah, N.V., Jhansi Lakshmi V, Pasalu I C, Katti G R and Padmavathi C 2008. Insecticides in rice IPM past, present and future. Technical Bulletin No.30. Directorate of Rice Research, Hyderabad, A.P. India 146.

Park, D.S., Lee S K, Lee J H, Song S Y, Kwak D Y, Yeo U S, Jeon N S, Park S $\mathrm{K}$, Song Y C, Nam M H, Ku Y C and Jeon J S 2007. The identification of candidate rice genes that confer resistance to the brown plant hopper (Nilaparvata lugens) through representational difference analysis. Theortical Applied Genetics, 115: 357547.

Singh, S.P., 2000. Bio-intensive approach helpful. The Hindu Survey of Indian Agriculture, 2: 159-163.

\section{How to cite this article:}

Vijay Kumar Soni and Tiwari, S.N. 2017. Glasshouse Evaluation of New Source of Resistance against Brown Plant Hopper Nilaparvata lugens (Stal) in Rice. Int.J.Curr.Microbiol.App.Sci. 6(9): 1187-1192. doi: https://doi.org/10.20546/ijcmas.2017.609.143 